\title{
FEASIBILITY AND EFFECT OF IMPLEMENTING PHYSICAL ACTIVITY PROGRAM IMPLEMENTATION DURING COVID-19 IN HOSPITALIZED POSITIVE COVID-19 OLDER ADULTS
}

\author{
L. ANDRE ${ }^{1}$, Y. ROLLAND ${ }^{1}$, S. GERARD ${ }^{1}$, M.-J. KERGOAT ${ }^{2}$, \\ E. PEYRUSQUÉ ${ }^{2,3}$, M. AUBERTIN-LEHEUDRE2,3
}

1. Gérontopôle, CHU Toulouse, Toulouse, France; UMR 1027, INSERM, Toulouse, France; 2. Centre de recherche de l'institut Universitaire de Gériatrie de Montréal (CRIUGM);

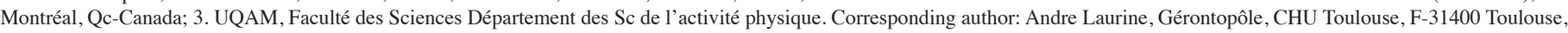
France; UMR 1027, INSERM, F-31400 Toulouse,France. andre.1@chu-toulouse.fr

\section{Main text}

Among individuals with covid-19 infection, around 2.9\% of patients will develop serious symptoms as respiratory failure and $19 \%$ of them will be hospitalized in intensive care units (1). In addition, epidemiological studies found that age is a risk factor of covid-19 hospitalization and mortality (1).

In older adults, hospitalization is recognized to lead to iatrogenic issues. Indeed, hospitalizations are associated with functional $(-33 \%)(2)$ and muscle strength $(-6 \%)$ declines. During covid-19, measures such as decreasing drastically social interactions in patient's room but also usual care such as physical rehabilitation activities have been implemented during hospitalization. However, even if these measures have been applied to protect the patient, they should be considered as accelerator risk factors of functional decline during hospitalization in older adults (3). In order to preserve or limit the physical and mental health declines (i.e. anxiety; stress), we implemented an unsupervised validated physical activity (PA) program (MATCH; $(4,5))$ in a short-stay Covid-19 geriatric unit, during the covid-19 European 1st wave (March to April 2020).

Our hypothesis was that MATCH program will be acceptable and may counteract physical and mental decline among older adults hospitalized in covid-19 unit. This program, carried out independently by the patients themselves, seemed to be particularly suited to the period of over-work of the health care professional and the containment conditions of infected patients. This was a pilot phase of a larger study ethically approved (\#20.04.08.48526), designed as a prospective, monocentric, proof-of-concept study. Short Physical Performances Battery (SPPB), Hospitalized Anxiety and Depression (HAD) scale, and Activities of Daily Living score (ADL) at baseline and at the end of the unit hospitalization were assessed by trained medical team. At baseline, the MATCH decisional tree (3 tests: 30 second chair test, balance with joint-feet and semi-tandem stance and 4 meters comfortable walking test) was also performed in order to prescribe and explain one of the five MATCH standardized program (3). This specific MATCH program should be done every day by patients themselves unsupervised. At the end of the intervention, self-satisfaction of the program was recorded.
During the period, 48 COVID-19 patients were hospitalized. Eleven patients ( 7 women, 4 men; age: $86.6 y e a r s(S D=6.3)$ ) were included in the MATCH intervention (see Table 1 for clinical characteristics). The others $(n=37)$ were excluded due to age lower than 75 years $(n=4)$, inability to pass the decisional tree tests $(n=23)$, severe dementia $(n=4)$, or severe disease complication $(n=3)$ or not proposed $(n=3)$.

Implementation of the MATCH intervention was feasible and took only 15-20 minutes for all tests required to complete the decisional tree. The exercise intervention length was 9.3 days on average. Moreover, the medical staff found it easy to learn and to teach the program. In addition, the program did not require specific materials and the ones used were very easy to clean (plastic sets).

Feasibility (our main outcome), evaluated by the adherence of the intervention (number of completed exercise days /total intervention days) showed that the PA was done $53 \%$ of the time (from 26 to $80 \%$ ) and $82 \%$ of patient were satisfied. Importantly, $36 \%$ of the participants presented some medical issues that could limited the adherence. Moreover, another potential limitation on adherence reliability was that collecting data on program adherence was difficult due to the overload of the staff. Thus, missing data where coding as non-realized which may under estimating program adherence. Moreover, walking program was limited because of the room isolation and space. Since this pilot study, in our geriatric covid-19 unit, we dedicated a specific place out of their room to practice that kind of exercise. In addition, during the study (due to covid19 restriction), visits of family or caregivers were not allowed in the unit and could not be involved or support (motivation) their relatives. To avoid this difficulty, it would be interesting to implicate the paramedical team to 1) motivate the patients when they see him or her; 2) collect adherence since the unit-team also work on the week-ends leading to a better collection. We were not able to show significant improvement on ADL score, anxiety or depression scores or physical performances, but the study design was not developed to detect these changes and the sample size was small. However, even with a limited sample size, ADL improved clinically (mean change: +0.4 points) and tend to be statistically significant $(\mathrm{p}=0.0552)$.

In conclusion, implementing the MATCH program is feasible in short-stay geriatric covid-19 unit, acceptable for Published online January 30, 2021, http:/ / dx.doi.org/10.1007/ s12603-021-1596-4 
Table 1

Subjects characteristics and outcomes changes at the end of the intervention $(\mathrm{N}=11)$

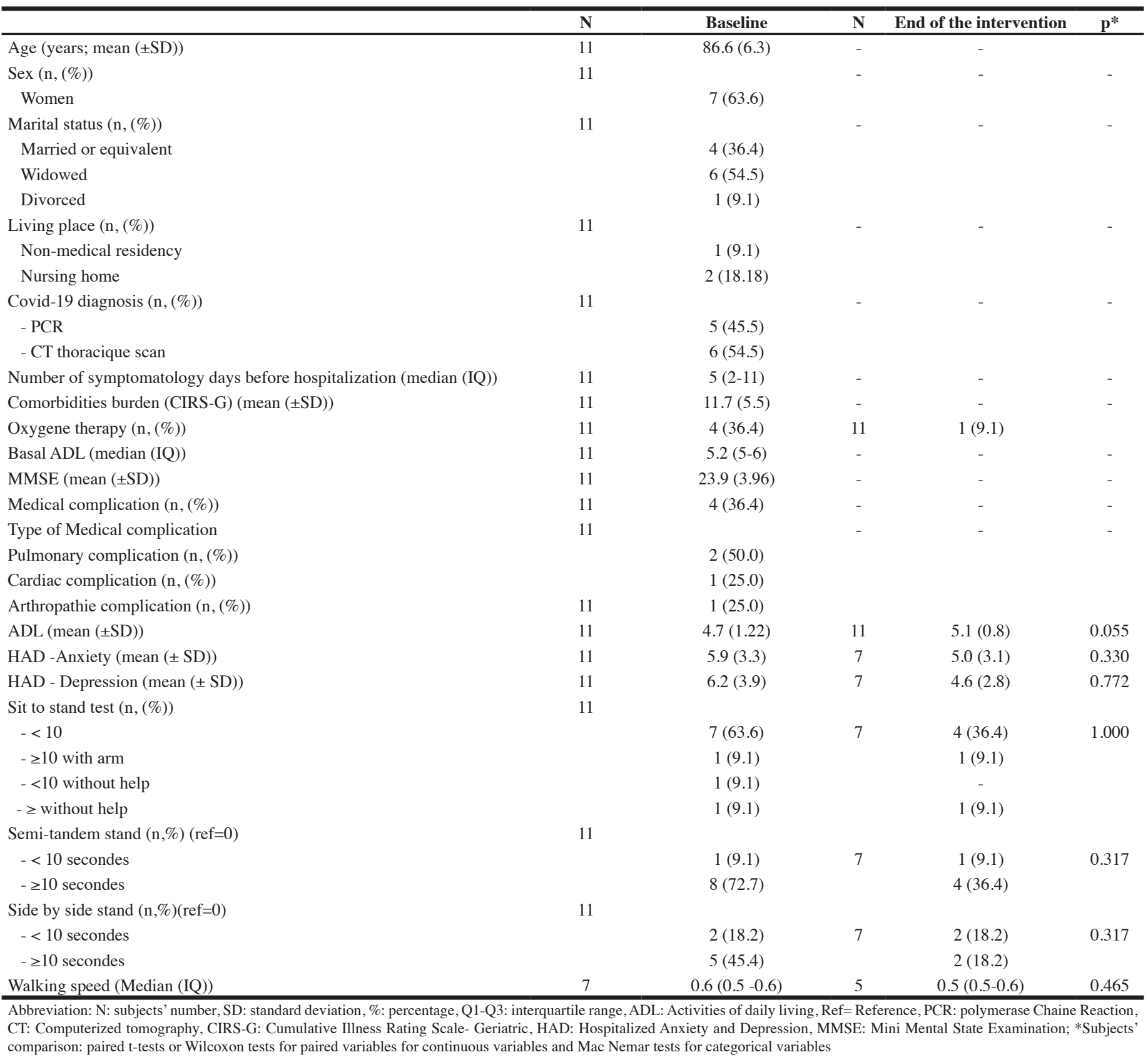

professional team and patients and would be beneficial to improve or preserve ADL in older adults. Further research with larger sample size and control group are needed to confirm these results.

Ethical statement: The study was ethically approved (\#20.04.08.48526) and respected the current laws of the country.

Conflict of Interest: Laurine Andre, Yves Rolland, Stéphane Gerard, Marie-Jeanne Kergoat, Eva Peyrusqué, Mylène Aubertin-Leheudre have no conflicts of interest directly relevant to the content of this study.
Funding sources: This study was supported by the «Appel à projets Recherche et Innovation Flash Covid 2020" of the teaching hospital of Toulouse

Acknowledgments: Laurine Andre, Yves Rolland, Stéphane Gerard, Marie-Jeanne Kergoat, Eva Peyrusqué, Mylène Aubertin-Leheudre contributed significantly to the study conception, the writing of the manuscript and approved the final version. The authors would like to thank Dr Sara Vienne-Noyes for her clinical investigation as investigator

\section{References}

1. Salje H, Tran Kiem C, Lefrancq N, Courtejoie N, Bosetti P, Paireau J, et al. Estimating the burden of SARS-CoV-2 in France. Science. 10 2020;369(6500):208-11.

2. Buurman BM, Hoogerduijn JG, de Haan RJ, Abu-Hanna A, Lagaay AM, Verhaar HJ, 


\section{FEASIBILITY AND EFFECT OF IMPLEMENTING PHYSICAL ACTIVITY PROGRAM IMPLEMENTATION}

et al. Geriatric Conditions in Acutely Hospitalized Older Patients: Prevalence and OneYear Survival and Functional Decline. PLoS One [Internet]. 14 nov 2011 [cité 29 sept 2020];6(11). Disponible sur: https://www.ncbi.nlm.nih.gov/pmc/articles/PMC3215703/

3. Aubertin-Leheudre M, Rolland Y. The Importance of Physical Activity to Care for Frail Older Adults During the COVID-19 Pandemic. J Am Med Dir Assoc. juill 2020;21(7):973-6.
4. Juneau A, Bolduc A, Nguyen P, Leclerc B-S, Rousseau J, Dubé F, et al. Feasibility of Implementing an Exercise Program in a Geriatric Assessment Unit: the SPRINT Program. Can Geriatr J. 30 sept 2018;21(3):284-9.

5. Carvalho TC, Valle AP do, Jacinto AF, Mayoral VF de S, Boas PJFV, Carvalho TC, et al. Impact of hospitalization on the functional capacity of the elderly: A cohort study. Revista Brasileira de Geriatria e Gerontologia. avr 2018;21(2):134-42. 